\title{
ALGEBRAIC OPERATIONS ON HIGHER-DIMENSIONAL MATRICES USING ASSEMBLY LANGUAGE PROGRAM IN INTEL 8085 MICROPROCESSOR
}

\author{
${ }^{1}$ Mohammed Ibrahim .A \& ${ }^{2}$ Malarvizhi .V \\ ${ }^{1}$ Master Student \\ Department of Physics \\ Pachaiyappa's College, Shenoy Nagar, Chennai-600030. India \\ Email:mi551212550@hotmail.com \\ ${ }^{2}$ Associate Professor \\ Department of Physics \\ Pachaiyappa's College, Shenoy Nagar, Chennai-600030. India \\ Email:malarveliah@gmail.com
}

\begin{abstract}
The algebraic operations on lower-order matrices are a simple and easy one. But for higher dimensional matrix the operations are trivial to do manually. In this project we intend to do algebraic operations like addition, subtraction, multiplication of higher dimensional matrix (maximum of 16×16) by using Intel 8085 microprocessor assembly language program (ALP). The reason for choosing the above dimensional limit is that we have small memory sized RAM. The elements of the matrices are restricted to a positive real hexadecimal number since the registers can hold an only positive hexadecimal number.
\end{abstract}

Keywords: intel-8085, matrix algebra, programmer model, hexadecimal.

\section{INTRODUCTION}

Matrix algebra is very important as it has a wide application in various fields. An algebraic operation like addition, subtraction, multiplication, scalar multiplication and inverse can be done on matrices with certain rules and regulations. The dimension of a matrix is represented by $(\mathbf{m} \times \mathbf{n})$, where $m$ and $n$ represent the number of rows and column respectively. Also known as the order of a matrix. Where,

\section{$\mathbf{m}, \mathbf{n} \in \mathbb{Z}+$}

The Intel 8085 microprocessor is an 8-bit processor. The programmer model shown in Fig. 1 helps the programmer to understand the memory organization of internal memories. It consists of two 
blocks namely, register block and memory block. The register block consists of an accumulator, six general purpose register which is 8-bit. Besides they have stack pointer and program counter which are 16-bit. The memory block consists of $2 \mathrm{~K}$ EPROM where the utility programs are stored and $2 \mathrm{~K}$ RAM where the user programs are stored. Each memory in the memory block can hold an 8-bit value which is addressed by 16-bit numbers. These two blocks are connected by parallel lines namely address bus, data bus and control bus.

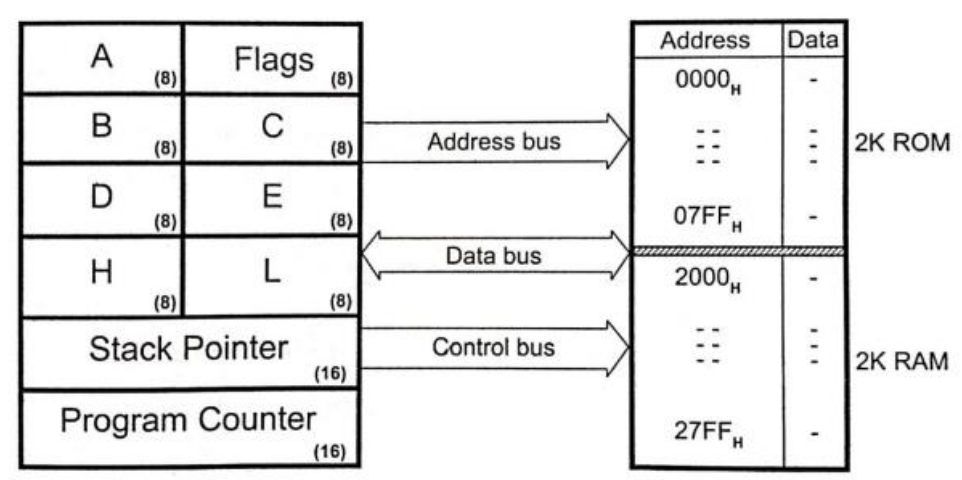

Fig. 1: Programmer model of 8085

\section{CONSTRAINTS}

Since the memory addresses are named with hexadecimal numbers and the data hold by memories and registers are (8-bit) 2 digit hexadecimal number, we have to formulate the problem with certain rules. They are,

- The elements of the matrix and the indices described in this project are hexadecimal numbers.

- The order of the matrix is given in decimal number.

- The starting address of RAM (user's program area) is considered to be $4000_{\mathrm{H}}$.

- The maximum order of the matrix is $16 \times 16$.

- The program can be modified to do operations of matrices of dimension within the above limit. An example we can do operations on $(2 \times 10)$ matrix and so on.

\section{MATRIX ADDITION AND SUBTRACTION}

In general, the element of a matrix is represented by " $\mathrm{X}_{\mu \vartheta}$ " and the matrix itself represented as

$$
\mathbf{X}=\left[\mathbf{X}_{\mu \vartheta}\right] \mathrm{m \times n} .
$$

Where the $m \times n$ is the order of the matrix $\mathbf{X}$ and $\mu, \vartheta$ are the indices which represent the $\mu^{\text {th }}$ row and $\vartheta^{\text {th }}$ column.

i.e. $X=\left[x_{\mu \vartheta}\right]_{m \times n}$ and $Y=\left[y_{\mu \vartheta}\right]_{m \times n}$ then $X \pm Y=\left[x_{\mu \vartheta} \pm y_{\mu \vartheta}\right]_{m \times n}$. 


\section{Doing with ALP:}

Memory mapping: In order to distribute the matrix elements in the memory of RAM, we can consider the last two number of the memory address represent the row and column such that "ZZ $\mu \vartheta "$.

For example,

\begin{tabular}{|c|c|}
\hline Memory address & Data \\
\hline $\mathbf{4 1 5 1}$ & $0 \mathrm{~A}_{\mathrm{H}}$ \\
\hline
\end{tabular}

$0 \mathrm{~A}_{\mathrm{H}}$ is the element of the matrix of 5 th row and 1 st column of the corresponding matrix. Here $\mu$ and $\vartheta$ are indices such that,

$$
\mu, \vartheta \in 0,1,2, \ldots \ldots . .9, \mathrm{~A}, \mathrm{~B}, \mathrm{C}, \mathrm{D}, \mathrm{E}, \mathrm{F} .
$$

Let us consider an addend/subtrahend matrix $\mathbf{X}$ of order $(16 \times 16)$, whose elements are located in memory $4100_{\mathrm{H}}$ to $41 \mathrm{FF}_{\mathrm{H}}$. There are 256 elements in the matrix.

$$
X=\left[\begin{array}{cccccccc}
x_{00} & x_{01} & x_{02} & \cdot & \cdot & \cdot & \cdot & x_{0 F} \\
x_{10} & x_{11} & x_{12} & \cdot & \cdot & \cdot & \cdot & \cdot \\
x_{20} & x_{21} & x_{22} & \cdot & \cdot & \cdot & \cdot & \cdot \\
\cdot & \cdot & \cdot & \cdot & \cdot & \cdot & \cdot & \cdot \\
\cdot & \cdot & \cdot & \cdot & \cdot & \cdot & \cdot & \cdot \\
\cdot & \cdot & \cdot & \cdot & \cdot & x_{\mu \vartheta} & \cdot & \cdot \\
\cdot & \cdot & \cdot & \cdot & \cdot & \cdot & \cdot & \cdot \\
x_{F 0} & \cdot & \cdot & \cdot & \cdot & \cdot & \cdot & x_{F F}
\end{array}\right]
$$

Here how the elements are distributed in memories for this matrix is given in Table.1.

\begin{tabular}{|c|c|}
\hline Memory address & Data \\
\hline $\mathbf{4 1 0 0}$ & $x_{00}$ \\
\hline $\mathbf{4 1 0 1}$ & $x_{01}$ \\
\hline $\mathbf{4 1 0 2}$ & $x_{02}$ \\
\hline $\mathbf{4 1 0 3}$ & $x_{03}$ \\
\hline$\cdot$ & $\cdot$ \\
\hline$\cdot$ & $\cdot$ \\
\hline $\mathbf{4 1} \boldsymbol{\mu} \boldsymbol{\vartheta}$ & $x_{\boldsymbol{\mu} \vartheta}$ \\
\hline$\cdot$ & $\cdot$ \\
\hline $\mathbf{4 1 F F}$ & $x_{F F}$ \\
\hline
\end{tabular}

Table. 1 
Similarly, let the augend/minuend matrix $\mathbf{Y}=\left[\mathbf{y}_{\boldsymbol{\mu} 9}\right]_{16 \times 16}$ of the same order and their elements are located in memory $4200_{\mathrm{H}}$ to $42 \mathrm{FF}_{\mathrm{H}}$. For the sum/difference matrix $\mathbf{S}$, elements are located in memory $4300_{\mathrm{H}}$ to $43 \mathrm{FF}_{\mathrm{H}}$. Where,

$$
\begin{aligned}
& \mathbf{S}=\mathbf{X}+\mathbf{Y}=\left[\mathrm{x}_{\mu \vartheta}+\mathrm{y}_{\mu \vartheta}\right]_{16 \times 16}(\text { for addition operation }) . \\
& \mathbf{S}=\mathbf{Y}-\mathbf{X}=\left[\mathrm{y}_{\mu \vartheta}-\mathrm{x}_{\mu \vartheta}\right]_{16 \times 16}(\text { for subtraction operation }) .
\end{aligned}
$$

If the result of operation exceeds the value $\mathrm{FF}_{\mathrm{H}}$ in the case of addition or if the result of an operation is negative in the case of subtraction then the carry or borrow will be stored in a matrix $\mathbf{G}=\left[g_{\mu \vartheta}\right]_{16 \times 16}$ of same order respectively. The memory location allotted for this is from $4400_{\mathrm{H}}$ to $44 \mathrm{FF}_{\mathrm{H}}$.

\section{ALGORITHM FOR ADDITION/SUBTRACTION}

Step 1: Load the number ' $\mathrm{n}$ ' in the E register. Where, $\mathrm{n}=\left\{\left(\mu \times 1 \mathrm{H}_{\mathrm{H}}\right)-1 \mathrm{H}\right\}, \mathrm{n}$ should be a hexadecimal number. $\mu$ is the number of rows of the matrix.

Step 2: Load the address of the $1^{\text {st }}$ element of the addend/subtrahend matrix in the $\mathrm{BC}$ register pair (data pointer) pair.

Step 3: Copy the element specified by data pointer to the accumulator and then to $\mathrm{H}$ register.

Step 4: Move the data pointer to the first element of the augend/minuend matrix.

Step 5: Copy the element to accumulator and proceed with the addition/subtraction operation with the $\mathrm{H}$ register.

Step 6: Check if there is a carry/borrow. If there is no carry/borrow jump to Step 10.

Step 7: If carry/borrow produced, then store the result of the addition/subtraction by incrementing the data pointer to the sum/difference matrix $\mathbf{S}$.

Step 8: Now clear the accumulator and increment it by one.

Step 9: Again increment the data pointer to the carry/borrow matrix $\mathbf{G}$ and store the corresponding Carry/borrow and return to sum/difference matrix $\mathbf{S}$. and then jump to Step 11.

Step 10: Increment the data pointer to the sum/difference matrix $\mathbf{S}$ and store the result.

Step 11: Decrement the data pointer to the addend/subtrahend matrix $\mathbf{X}$.

Step 12: Now increment the data pointer to the next element of the same matrix.

Step 13: Now decrement the value of ' $n$ ' in the E register.

Step 14: Check if $\mathrm{n}$ is zero or non-zero. If it is a non-zero go to step 3 or else continue to next step.

Step 15: Once again repeat from Step 3 to Step 11. 
Step 16: End the program.

Flow chart:

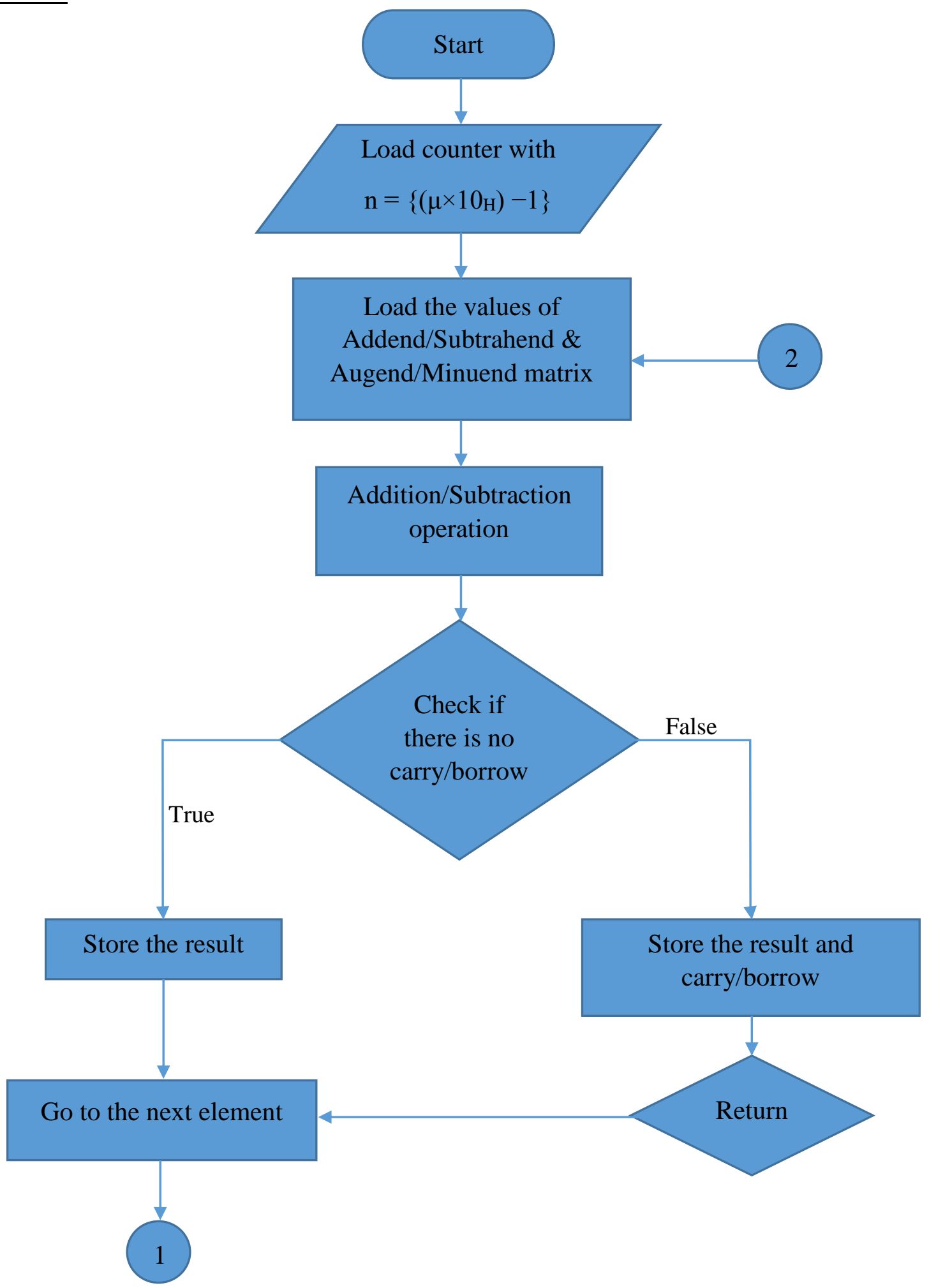




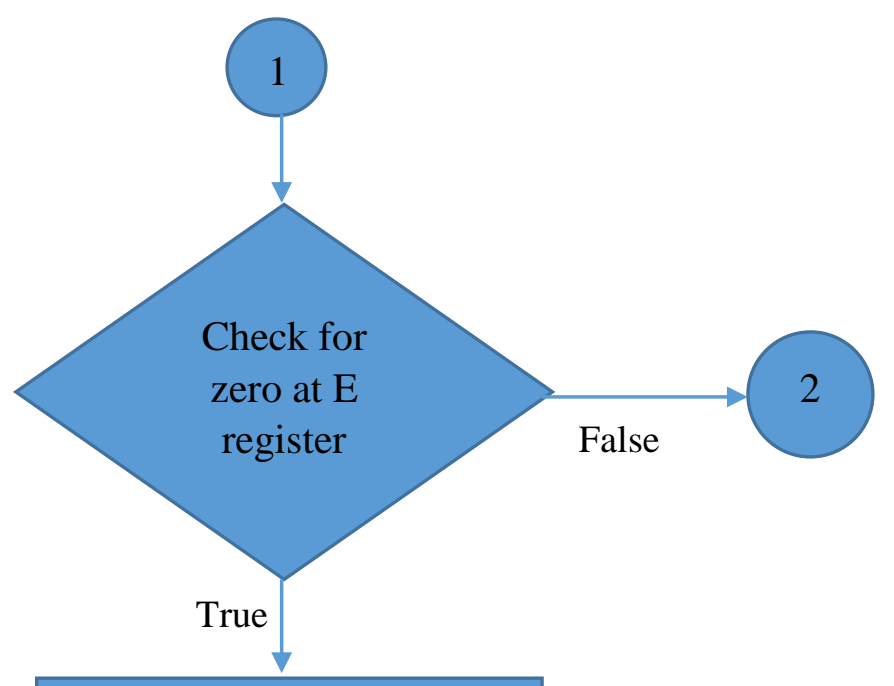

\section{Repeat only once}

End

CODE FOR ADDITION/SUBTRACTION

MVI E, $\mathrm{FF}_{\mathrm{H}}$

LXI B,4100H

J3: LDAX B

MOV H,A

INR B

LDAX B

ADD H / SUB H

JNC J1

INR B

STAX B

INR B

XRA A
INR A

STAX B

DCR B

JMP J2

J1: INR B

STAX B

J2: DCR B

DCR B

INX B

DCR E

JNZ J3

LDAX B

MOV H,A

INR B 
LDAX B

ADD H / SUB H

JNC J4

INR B

STAX B

INR B

XRA A

INR A
DCR B

JMP J5

J4: INR B

STAX B

J5: DCR B

DCR B

HLT

\section{STAX B}

What if a matrix is other than $(16 \times 16)$ ?

Whatever the type of matrix, the way of distributing the elements are the same as in matrix $\mathbf{X}$. The only thing matters are the number of rows. The number of rows of the required matrix should be taken as $\mu$ (maximum $10_{\mathrm{H}}$ ) in the formula given in step 1 of the algorithm.

The program is verified using 8085 simulator v 1.0 (designed by J-Tech Software).

\section{INPUT FOR ADDITION}

For simplicity, Matrix $\mathbf{X}$ can be considered to have all the elements as $01_{\mathrm{H}}$. The simulation input of matrix $\mathbf{X}$ is shown in Fig. 2. And the matrix $\mathbf{Y}$ is considered to have $02_{\mathrm{H}}$ as its elements except for the diagonal elements. The diagonal elements are loaded with $\mathrm{FF}_{\mathrm{H}}$ to check whether we get a diagonal carry matrix. The simulation input of matrix $\mathbf{Y}$ is shown in Fig. 3.

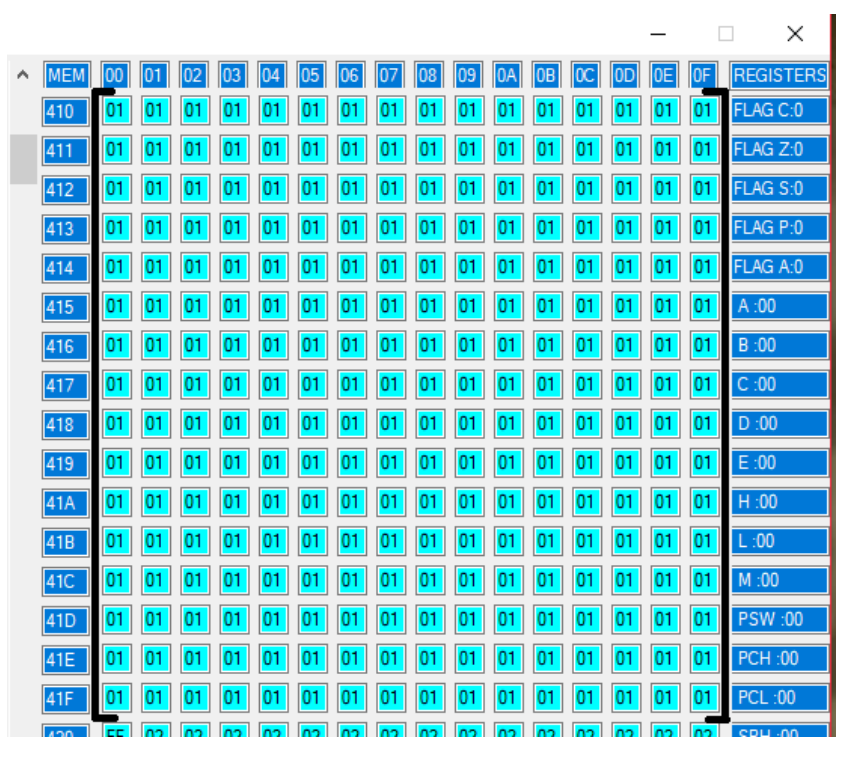

Fig. 2: Matrix X 
The black colour square bracket is marked in the figure to indicate the matrix bracket. It was not present in the simulator.

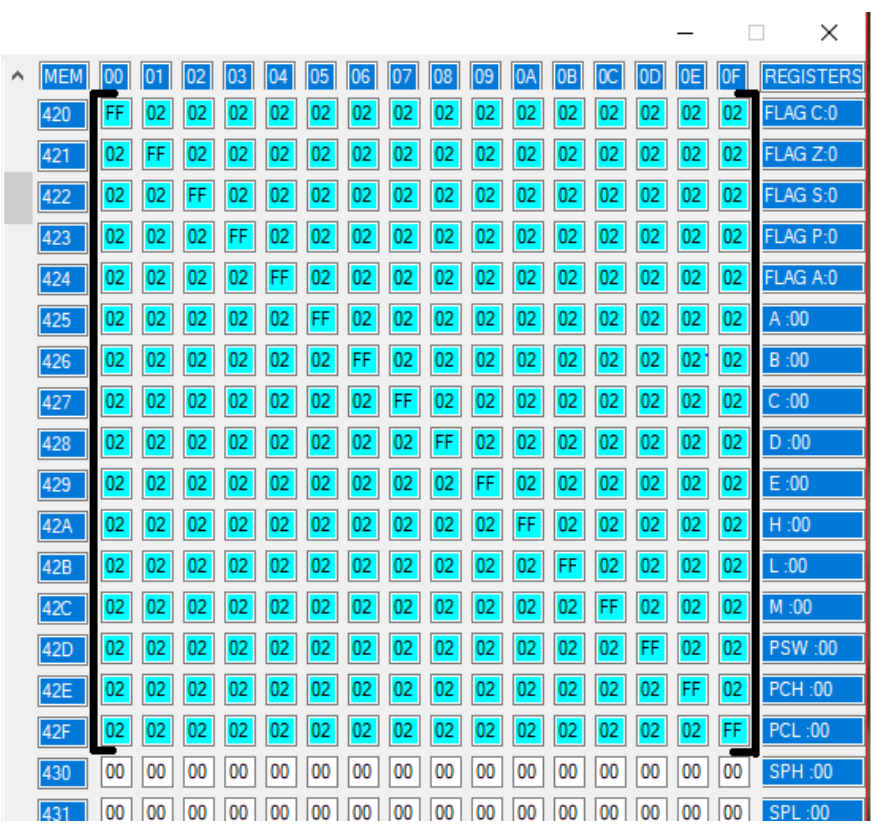

Fig. 3: Matrix Y

\section{OUTPUT FOR ADDITION}

The sum matrix $\mathbf{S}$ and the carry matrix $\mathbf{G}$ which we obtained are shown in Fig.4 and Fig.5 respectively. As we expect, the numbers on non-diagonal elements are $03_{\mathrm{H}}$. Since, $01_{\mathrm{H}}+02_{\mathrm{H}}=$ $03_{\mathrm{H}}$. And we obtained the carries at the diagonal as we expected. Since we have entered $\mathrm{FF}_{\mathrm{H}}$ in the diagonals of augend matrix Y. Therefore $01_{\mathrm{H}}+\mathrm{FF}_{\mathrm{H}}=0100_{\mathrm{H}} \cdot\left(01_{\mathrm{H}}\right.$ at carry matrix and $00_{\mathrm{H}}$ at sum matrix).

\begin{tabular}{|c|c|c|c|c|c|c|c|c|c|c|c|c|c|c|c|c|c|c|}
\hline & & & & & & & & & & & & & & & & & & \\
\hline MEN & 1 & 01 & & & 04 & & 06 & 07 & & & & & & & & [OE] & & \begin{tabular}{|l|l|} 
REGISTERS \\
\end{tabular} \\
\hline 4330 & 00 & 03 & 03 & 03 & 03 & 03 & 03 & 03 & 03 & 0 & & 03 & 03 & 03 & 03 & 03 & 03 & FLAG C:0 \\
\hline 431 & 03 & 00 & 03 & 03 & 03 & 03 & 03 & 03 & 03 & 10 & & 03 & 03 & 03 & 03 & 03 & 03 & FLAG Z:0 \\
\hline \begin{tabular}{|l|l|}
432 \\
\end{tabular} & 03 & 03 & 00 & 03 & 03 & 03 & 03 & 03 & 03 & 0 & & 03 & 03 & 03 & 03 & 03 & 03 & FLAG S:0 \\
\hline 4 & 03 & 03 & 03 & 00 & 03 & 03 & 03 & 03 & 03 & & & 03 & 03 & 03 & 03 & 03 & 03 & FLAG P:1 \\
\hline \begin{tabular}{|l|l|}
4344 \\
\end{tabular} & 03 & 03 & 03 & 03 & 00 & 03 & 03 & 03 & 03 & & & 03 & 03 & 03 & 03 & 03 & 03 & FLAG A:D \\
\hline 4035 & 03 & 03 & 03 & 03 & 03 & 00 & 03 & 03 & 03 & 0 & & 03 & 03 & 03 & 03 & 03 & 03 & $A: 01$ \\
\hline \begin{tabular}{|l|}
436 \\
\end{tabular} & 03 & 03 & 03 & 03 & 03 & 03 & 00 & 03 & 03 & $\sqrt{0}$ & & 03 & 03 & 03 & 03 & 03 & 03 & B:41 \\
\hline 437 & 03 & 03 & 03 & 03 & 03 & 03 & 03 & 00 & 03 & 0 & & 03 & 03 & 03 & 03 & 03 & 03 & C:FF \\
\hline 438 & 03 & 03 & 03 & 03 & 03 & 03 & 03 & 03 & a & 0 & 3 & 03 & 03 & 03 & 03 & 03 & 03 & $D: 00$ \\
\hline 439 & 03 & 03 & 03 & 03 & 03 & 03 & 03 & 03 & 03 & 0 & & 03 & 03 & 03 & 03 & 03 & 03 & E:00 \\
\hline $43 \mathrm{~A}$ & 03 & 03 & 03 & 03 & 03 & 03 & 03 & 03 & 03 & 0 & 3 & 00 & 03 & 03 & 03 & 03 & 03 & $\mathrm{H}: 01$ \\
\hline 4338 & 03 & 03 & 03 & 03 & 03 & 03 & 03 & 03 & 03 & & 3 & 03 & 00 & 03 & 03 & 03 & 03 & L.:00 \\
\hline $43 C$ & 03 & 03 & 03 & 03 & 03 & 03 & 03 & 03 & 03 & 0 & 3 & 03 & 03 & 00 & 03 & 03 & 03 & $M: 00$ \\
\hline 430 & 03 & 03 & 03 & 03 & 03 & 03 & 03 & 03 & 03 & {$[0$} & 3 & 03 & 03 & 03 & 00 & 03 & 03 & \begin{tabular}{|l|l|} 
PSW :04 \\
\end{tabular} \\
\hline $43 E$ & 03 & 03 & 03 & 03 & 03 & 03 & 03 & 03 & 03 & 0 & & 03 & 03 & 03 & 03 & 00 & 03 & PCH :00 \\
\hline $43 \mathrm{~F}$ & 03 & 03 & 03 & 03 & 03 & 03 & 03 & 03 & 03 & 0 & & 03 & 03 & 03 & 03 & 03 & 00 & PCL :00 \\
\hline
\end{tabular}

Fig. 4: Sum Matrix S 


\begin{tabular}{|c|c|c|c|c|c|c|c|c|c|c|c|c|c|c|c|c|c|}
\hline & & & & & & & & & & & & & & & & & \\
\hline MEM & & 01 & & & & & & & & & & & & & $\mathrm{DE}$ & OF & REGISTERS \\
\hline 4 & 01 & 00 & 00 & 00 & 00 & 00 & 00 & 00 & 00 & 00 & 00 & 00 & 00 & 00 & 00 & 00 & FLAG C:0 \\
\hline & 00 & 01 & 00 & 00 & 00 & 00 & 00 & 00 & 00 & 00 & 00 & 00 & 00 & 00 & 00 & 00 & LAG Z:0 \\
\hline & 00 & 00 & 01 & 00 & 00 & 00 & 00 & 00 & 00 & 00 & 00 & 00 & 00 & 00 & 00 & 00 & FLAG S:0 \\
\hline & 00 & 00 & 00 & 01 & 00 & 00 & 00 & 00 & 00 & 00 & 00 & 00 & 00 & 00 & 00 & 00 & FLAG P:1 \\
\hline & 00 & 00 & 00 & 00 & 01 & 00 & 00 & 00 & 00 & 00 & 00 & 00 & 00 & 00 & 00 & 00 & FLAG A:O \\
\hline & 00 & 00 & 00 & 00 & 00 & 01 & 00 & 00 & 00 & 00 & 00 & 00 & 00 & 00 & 00 & 00 & $A: 01$ \\
\hline & 00 & 00 & 00 & 00 & 00 & 00 & 01 & 00 & 00 & 00 & 00 & 00 & 00 & 00 & 00 & 00 & $B: 41$ \\
\hline & 00 & 00 & 00 & 00 & 00 & 00 & 00 & 01 & 00 & 00 & 00 & 00 & 00 & 00 & 00 & 00 & $C: F F$ \\
\hline & 00 & 00 & 00 & 00 & 00 & 00 & 00 & 00 & 01 & 00 & 00 & 00 & 00 & 00 & 00 & 00 & $D: 00$ \\
\hline & 00 & 00 & 00 & 00 & 00 & 00 & 00 & 00 & 00 & 01 & 00 & 00 & 00 & 00 & 00 & 00 & $E: 00$ \\
\hline & 00 & 00 & 00 & 00 & 00 & 00 & 00 & 00 & 00 & 00 & 01 & 00 & 00 & 00 & 00 & 00 & $\mathrm{H}: 01$ \\
\hline & 00 & 00 & 00 & 00 & 00 & 00 & 00 & 00 & 00 & 00 & 00 & 01 & 00 & 00 & 00 & 00 & L:00 \\
\hline & 00 & 00 & 00 & 00 & 00 & 00 & 00 & 00 & 00 & 00 & 00 & 00 & 01 & 00 & 00 & 00 & $\bar{M}: 00$ \\
\hline & 00 & 00 & 00 & 00 & 00 & 00 & 00 & 00 & 00 & 00 & 00 & 00 & 00 & 01 & 00 & 00 & $\begin{array}{l}\text { PSW : } 04 \\
\end{array}$ \\
\hline & 00 & 00 & 00 & 00 & 00 & 00 & 00 & 00 & 00 & 00 & 00 & 00 & 00 & 00 & 01 & 00 & PCH : 00 \\
\hline & & 00 & 00 & 00 & 00 & 00 & 00 & 00 & 00 & 00 & 00 & 00 & 00 & 00 & 00 & 01 & PCL :00 \\
\hline
\end{tabular}

Fig. 4: Carry matrix G

\section{INPUT FOR SUBTRACTION}

Matrix $\mathbf{X}$ can be considered to have all the non-diagonal elements as $01_{\mathrm{H}}$ and the diagonal elements as $02_{\mathrm{H}}$. The simulation input of matrix $\mathbf{X}$ is shown in Fig. 6 . And the matrix $\mathbf{Y}$ is considered to have $02 \mathrm{H}$ as its non-diagonal elements and the diagonal elements are loaded with $01_{\mathrm{H}}$ to check whether we get a diagonal (negative) borrow matrix. But the difference should be still $01_{\mathrm{H}}$. The simulation input of matrix $\mathbf{Y}$ is shown in Fig. 7.

\begin{tabular}{|c|c|c|c|c|c|c|c|c|c|c|c|c|c|c|c|c|c|}
\hline MEM & & 01 & 02 & 03 & 04 & 05 & 06 & 07 & 08 & 09 & DA & $0 \mathrm{~B}$ & DC & $D$ & DE & OF & REGISTERS \\
\hline 410 & 02 & \begin{tabular}{|l|l|}
01 \\
\end{tabular} & 01 & 01 & 01 & 01 & 01 & 01 & 01 & \begin{tabular}{|l|}
01 \\
\end{tabular} & 01 & 01 & 01 & 01 & 01 & 01 & FLAG C:0 \\
\hline & 01 & 02 & 01 & 01 & 01 & 01 & 01 & 01 & 01 & 01 & 01 & 01 & 01 & 01 & 01 & 01 & FLAG $Z: 0$ \\
\hline & 01 & 01 & 02 & 01 & 01 & 01 & 01 & 01 & 01 & 01 & 01 & 01 & 01 & 01 & 01 & 01 & FLAG S:0 \\
\hline & 01 & 01 & 01 & \begin{tabular}{|l|}
02 \\
\end{tabular} & 01 & 01 & 01 & 01 & 01 & 01 & 01 & 01 & 01 & 01 & 01 & 01 & FLAG P:0 \\
\hline & 01 & 01 & 01 & 01 & 02 & 01 & 01 & 01 & 01 & 01 & 01 & 01 & 01 & 01 & 01 & 01 & FLAG A:0 \\
\hline & 01 & 01 & 01 & 01 & 01 & 02 & 01 & 01 & 01 & 01 & 01 & 01 & 01 & 01 & 01 & 01 & $A: 00$ \\
\hline & 01 & 01 & 01 & 01 & 01 & 01 & 02 & 01 & 01 & 01 & 01 & 01 & 01 & 01 & 01 & 01 & $\mathrm{~B}: 00$ \\
\hline & 01 & 01 & 01 & 01 & 01 & 01 & 01 & 02 & 01 & 01 & 01 & 01 & 01 & 01 & 01 & 01 & $C: 00$ \\
\hline & 01 & \begin{tabular}{|l|l|}
01 \\
\end{tabular} & 01 & \begin{tabular}{|l|}
01 \\
\end{tabular} & 01 & 01 & 01 & 01 & 02 & 01 & 01 & 01 & 01 & 01 & 01 & 01 & $D: 00$ \\
\hline & \begin{tabular}{|l|}
01 \\
\end{tabular} & \begin{tabular}{|l|}
01 \\
\end{tabular} & 01 & 01 & 01 & 01 & 01 & 01 & 01 & 02 & 01 & 01 & 01 & 01 & 01 & 01 & $E: 00$ \\
\hline & 01 & 01 & 01 & 01 & 01 & 01 & 01 & 01 & 01 & 01 & 02 & 01 & 01 & 01 & 01 & 01 & $\mathrm{H:00}$ \\
\hline & 01 & 01 & 01 & \begin{tabular}{|l|}
01 \\
\end{tabular} & 01 & 01 & 01 & 01 & 01 & 01 & 01 & 02 & 01 & 01 & 01 & 01 & $L: 00$ \\
\hline & 01 & 01 & 01 & 01 & 01 & 01 & 01 & 01 & 01 & 01 & 01 & 01 & 02 & 01 & 01 & 01 & $M: 00$ \\
\hline & 01 & 01 & 01 & 01 & 01 & 01 & 01 & 01 & 01 & 01 & 01 & 01 & 01 & 02 & 01 & 01 & PSW :00 \\
\hline & 01 & 01 & 01 & 01 & 01 & 01 & 01 & 01 & 01 & 01 & 01 & 01 & 01 & 01 & 02 & 01 & PCH :00 \\
\hline & 01 & 01 & 01 & 01 & 01 & 01 & 01 & 01 & 01 & 01 & 01 & 01 & 01 & 01 & 01 & 02 & PCL:00 \\
\hline
\end{tabular}

Fig. 5: Matrix X 


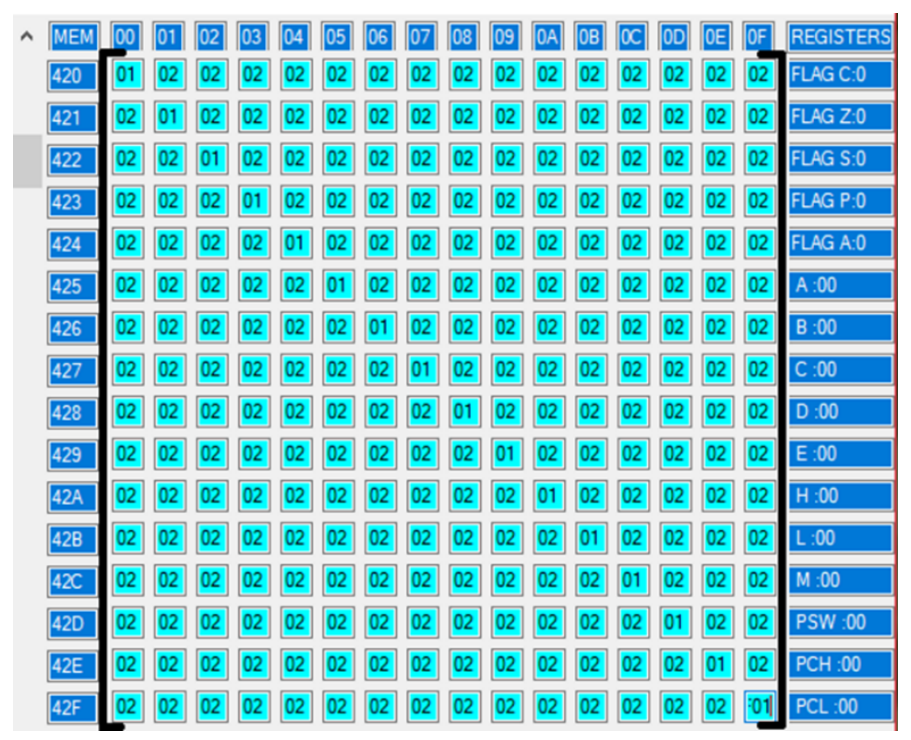

Fig. 6: Matrix Y

\section{OUTPUT FOR SUBTRACTION}

The difference matrix $\mathbf{S}$ and borrow matrix $\mathbf{G}$ which we obtain are shown in Fig. 8 and Fig. 9 respectively.

As we expect, all the elements of difference matrix $\mathbf{S}$ are $01_{\mathrm{H}}$. Since, the difference $\left(02_{\mathrm{H}} \sim 01_{\mathrm{H}}\right)$ is $01_{\mathrm{H}}$. We obtained the borrow matrix $\mathbf{G}$ with diagonal elements $01_{\mathrm{H}}$, which indicates that the diagonal elements in difference matrix $\mathbf{S}$ are negative.

\begin{tabular}{|c|c|c|c|c|c|c|c|c|c|c|c|c|c|c|c|c|c|}
\hline EM & & |01 | & & 03 & $\sqrt{0}$ & 05 & $\overline{0 E}$ & 07 & & & DA & & DC & | 00 & DEE || & & REGISTERS \\
\hline 430 & 01 & 01 & 01 & 01 & 01 & 01 & 01 & 01 & 01 & & 01 & & 01 & 01 & 01 & & FLAG C:0 \\
\hline 431 & 01 & 01 & 01 & 01 & 01 & 01 & 01 & 01 & 01 & 01 & 01 & 01 & 01 & 01 & 01 & 01 & FLAG Z:0 \\
\hline 432 & \begin{tabular}{|l|}
01 \\
\end{tabular} & 01 & 01 & 01 & 01 & 01 & 01 & 01 & 01 & 01 & 01 & 01 & 01 | & 01 & 01 & 01 & FLAG S:0 \\
\hline 433 & 01 & 01 & 01 & 01 & 01 & 01 & 01 & 01 & 01 & 01 & 01 & 01 [1 & 01 & 01 & 01 & 01 & FLAG P:1 \\
\hline 34 & \begin{tabular}{|l|l|}
01 & \\
\end{tabular} & 01 & 01 & 01 & 01 & 01 & 01 & 01 & 01 & 01 & 01 & 01 & \begin{tabular}{|l|l|}
01 \\
\end{tabular} & 01 & 01 & 01 & FLAG A:0 \\
\hline 35 & \begin{tabular}{|l|}
01 \\
\end{tabular} & 01 & 01 & 01 & 01 & 01 & 01 & 01 & 01 & 01 & 01 & 01 & 01 & 01 & 01 & 01 & A:FD \\
\hline 36 & 01 & 01 & 01 & 01 & 01 & 01 [ & 01 & 01 & 01 & 01 & 01 & 01 & 01 & 01 & 01 & 01 & $B: 41$ \\
\hline 437 & \begin{tabular}{|l|l|} 
& \\
\end{tabular} & 01 & 01 & 01 & 01 & 01 & 01 & 01 & 01 & 01 & 01 & 01 & \begin{tabular}{|l|}
01 \\
\end{tabular} & 01 & 01 & 01 & C:FF \\
\hline 438 & 01 & 01 & 01 & 01 & 01 & 01 & 01 & 01 & 01 [ & 01 & 01 & 01 & \begin{tabular}{|l|l|}
01 \\
\end{tabular} & 01 & 01 & 01 & $\mathrm{D}: 00$ \\
\hline 48 & \begin{tabular}{|l|l|}
01 & \\
\end{tabular} & 01 & 01 & 01 & 01 & 01 & 01 & 01 & 01 & \begin{tabular}{|l|l}
01 \\
\end{tabular} & 01 & 01 & \begin{tabular}{|l|l|}
01 \\
\end{tabular} & 01 & 01 & 01 & $E: 00$ \\
\hline $43 \mathrm{~A}$ & 01 & 01 & 01 & 01 & 01 & 01 & 01 & 01 & 01 & 01 & 01 & 01 & 01 & 01 & 01 & 01 & $\mathrm{H}: 02$ \\
\hline $3 \mathrm{~B}$ & 01 & 01 & 01 & 01 & 01 & 01 & 01 & 01 & 01 & \begin{tabular}{|l|}
01 \\
\end{tabular} & 01 & 01 & 01 & 01 & 01 & 01 & $L: 00$ \\
\hline${ }_{3} \mathrm{C}$ & 01 & 01 & 01 & 01 & 01 & 01 & \begin{tabular}{|l|l|}
01 \\
\end{tabular} & 01 & 01 & \begin{tabular}{|l|}
01 \\
\end{tabular} & 01 & 01 & 01 & 01 & 01 & 01 & M:00 \\
\hline 43D & 01 & 01 & 01 & 01 & 01 & 01 & 01 & 01 & 01 & 01 & 01 & 01 & 01 & 01 & 01 & 01 & PSW :04 \\
\hline & 01 & 01 & 01 & 01 & 01 & 01 & 01 & 01 & 01 & \begin{tabular}{|l|}
01 \\
\end{tabular} & 01 & 01 & 01 & 01 & 01 & 01 & PCH :00 \\
\hline & 01 & 01 & 01 & 01 & 01 & 01 & 01 & 01 & 01 & 01 & 01 & 01 & 01 & 01 & 01 & 01 & PCL: :00 \\
\hline
\end{tabular}

Fig. 7: Difference Matrix S

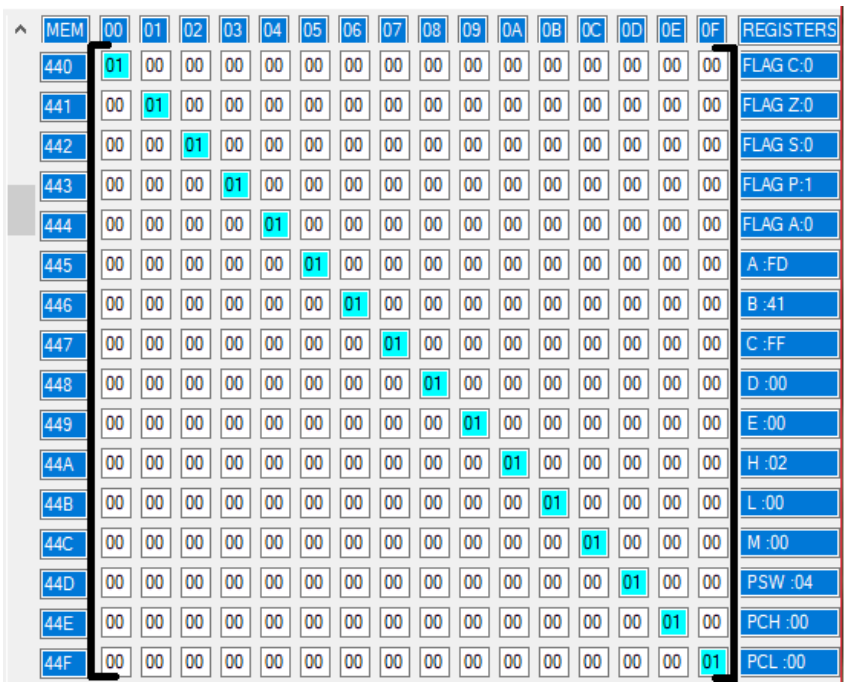

Fig. 8: Borrow Matrix 


\section{MATRIX MULTIPLICATION}

Let $\mathbf{X}=\left[\mathrm{x}_{\mu \vartheta}\right]_{m \times n}$ be the matrix of order $(\mathrm{m} \times \mathrm{n})$ and $\mathbf{Y}=\left[\mathrm{y}_{\mu \vartheta}\right]_{\mathrm{n} \times \mathrm{p}}$ be the matrix of order $(\mathrm{n} \times \mathrm{p})$ then the product matrix $\mathbf{X Y}$ will be the order of $(\mathrm{m} \times \mathrm{p})$. The actual procedure to do matrix multiplication is row-by-column multiplication rule. In 8085 system the data pointer moves linearly. Therefore, we require a very large number of instructions to do multiplication. So we design the code to follow the row-by-row multiplication instead of doing actual procedure. We can get the correct result by entering $\mathbf{Y}^{\mathbf{T}}$ instead of the $\mathbf{Y}$ matrix which is easy for the user to enter the data.

Doing with ALP:

Memory Mapping: The mapping procedure is similar to the previous case except for multiplicand matrix Y. In this case, we restrict our self that elements of the matrices are 4-bit hexadecimal numbers. So that the resultant element is within 16-bit.

Let us consider a multiplier matrix $\mathbf{X}=\left[\mathrm{x}_{\mu \vartheta}\right]_{16 \times 16}$ whose 4-bit elements are located in memory $4100_{\mathrm{H}}$ to $41 \mathrm{FF}_{\mathrm{H}}$ and multiplicand transpose matrix $\mathbf{Y}^{\mathbf{T}}=\left[\mathrm{y}_{\mu \vartheta}\right]^{\mathrm{T}}{ }_{16 \times 16}=\left[\mathrm{y}_{\vartheta \mu}\right]_{16 \times 16}$ whose 4-bit elements are located in memory $4200_{\mathrm{H}}$ to $42 \mathrm{FF}_{\mathrm{H}}$.

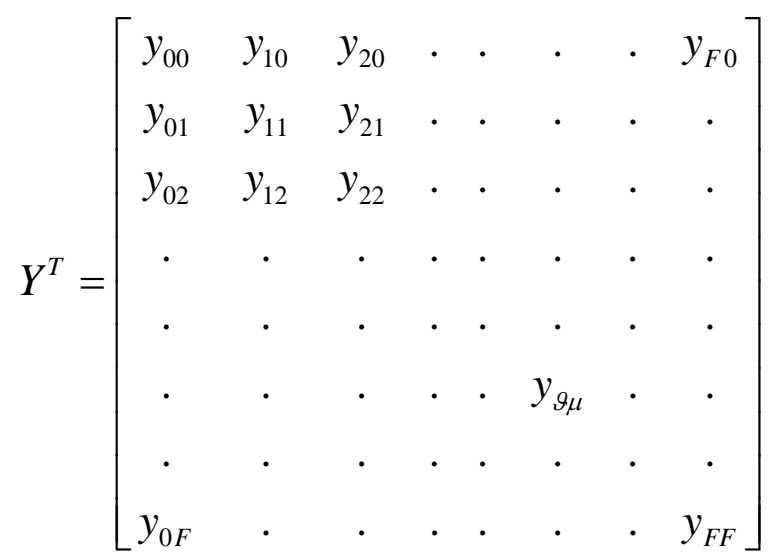

And the distribution of elements of $\mathbf{Y}^{\mathbf{T}}$ is given in Table. 2.

\begin{tabular}{|c|c|}
\hline Memory address & Data \\
\hline 4200 & $y_{00}$ \\
\hline 4201 & $y_{10}$ \\
\hline 4202 & $y_{20}$ \\
\hline . & . \\
\hline . & . \\
\hline • & . \\
\hline $42 \mu \vartheta$ & $y_{\vartheta_{\mu}}$ \\
\hline . & . \\
\hline • & . \\
\hline $42 \mathrm{FF}$ & $y_{F F}$ \\
\hline
\end{tabular}


For the product matrix $\mathbf{X Y}$, elements are defined as,

$$
X Y=\left[\begin{array}{cccccccc}
p_{00} & p_{01} & p_{02} & \cdot & \cdot & \cdot & \cdot & p_{0 F} \\
p_{10} & p_{11} & p_{12} & \cdot & \cdot & \cdot & \cdot & \cdot \\
p_{20} & p_{21} & p_{22} & \cdot & \cdot & \cdot & \cdot & \cdot \\
\cdot & \cdot & \cdot & \cdot & \cdot & \cdot & \cdot & \cdot \\
\cdot & \cdot & \cdot & \cdot & \cdot & \cdot & \cdot & \cdot \\
\cdot & \cdot & \cdot & \cdot & \cdot & p_{\mu \vartheta} & \cdot & \cdot \\
\cdot & \cdot & \cdot & \cdot & \cdot & \cdot & \cdot & \cdot \\
p_{F 0} & \cdot & \cdot & \cdot & \cdot & \cdot & \cdot & p_{F F}
\end{array}\right]
$$

Here, the resultant elements are obtained in memory locations described in the Table. 3.

\begin{tabular}{|c|c|c|c|c|c|c|}
\hline $\begin{array}{l}\text { Memory } \\
\text { address }\end{array}$ & Data & $\begin{array}{l}\text { Memory } \\
\text { address }\end{array}$ & Data & $\begin{array}{c}\text { Memory } \\
\text { address }\end{array}$ & Data & $\ldots$ \\
\hline 4300 & $p_{00}$ & 4400 & $p_{10}$ & 4500 & $p_{20}$ & $\ldots$ \\
\hline 4310 & $p_{01}$ & 4410 & $p_{11}$ & 4510 & $p_{21}$ & $\ldots$ \\
\hline 4320 & $p_{02}$ & 4420 & $p_{12}$ & 4520 & $p_{22}$ & $\ldots$ \\
\hline 4330 & $p_{03}$ & 4430 & $p_{13}$ & 4530 & $p_{23}$ & $\ldots$ \\
\hline . & . & . & . & . & . & ... \\
\hline . & . & • & . & • & • & ... \\
\hline . & . & . & . & . & . & ... \\
\hline 4390 & $p_{0 \vartheta}$ & $44 \vartheta 0$ & $p_{1 \vartheta}$ & 4590 & $p_{2 \vartheta}$ & $\ldots$ \\
\hline . & . & - & . & • & . & $\ldots$ \\
\hline . & . & • & . & • & . & ... \\
\hline . & . & • & . & • & . & ... \\
\hline $43 \mathrm{F0}$ & $p_{O F}$ & 44F0 & $p_{1 F}$ & $45 \mathrm{~F} 0$ & $p_{2 F}$ & $\ldots$ \\
\hline
\end{tabular}

If the product element exceeds $\mathrm{FF}_{\mathrm{H}}$ then the overlapping number is obtained in the next memory of the corresponding element.

\section{$\underline{\text { Programmer defined extra-memories }}$}

Apart from the memory location for program code and input/output data, there should be a 6 extra-memory location where the description of the matrix should be entered by the user as given in the Table. 4. 


\begin{tabular}{|c|c|c|}
\hline Memory address & Description & Value \\
\hline $\mathbf{5 2 0 0}$ & Storage counter (constant) & $02_{\mathrm{H}}$ \\
\hline $\mathbf{5 2 0 1}$ & No. of columns of matrix $\mathbf{X}$ & $10_{\mathrm{H}}$ \\
\hline $\mathbf{5 2 0 2}$ & No. of columns of product matrix minus one & $\boldsymbol{\beta}_{\mathbf{H}}=\boldsymbol{\alpha}_{\mathbf{H}}-1$ \\
\hline $\mathbf{5 2 0 3}$ & No. of columns of the product matrix & $\boldsymbol{\alpha H}_{\mathbf{H}}$ \\
\hline $\mathbf{5 3 0 0}$ & Temporary storage (for the program itself) & $\begin{array}{c}\text { Forbidden for } \\
\text { user }\end{array}$ \\
\hline $\mathbf{5 3 0 1}$ & Temporary address storage (for the program \\
& itself) & $\begin{array}{c}\text { Forbidden for } \\
\text { user }\end{array}$ \\
\hline
\end{tabular}

Table. 4

\section{ALGORITHM FOR MULTIPLICATION}

\section{Main program}

Step 1: Load DE register pair with $40 \mathrm{~F}_{\mathrm{H}}$ (starting address $-10_{\mathrm{H}}$ ) of $\mathbf{X}$.

Step 2: HL pair with $0010_{\mathrm{H}}$ and then double add the DE and HL register pair.

Step 3: Exchange the DE (data pointer-1) and HL register pairs.

Step 4: Store the value of E register in the temporary address storage location.

Step 5: Load BC (data pointer-2) and go to the subroutine program.

Step 6: Recover the value of E register from temporary address storage and go to subroutine program.

Step 7: Load the value from address 5202 and decrement it by one. Store it in address 5202 . Check the value $\left(\beta_{\mathrm{H}}-1\right)$, if it is non-zero then go to step- 6 or else continue to next step.

Step 8: Load the actual value of $\beta_{\mathrm{H}}$ in the memory address 5202 .

Step 9: Increment the storage counter.

Step 10: Recover the value of E register from temporary address storage.

Step 11: Load the value from address 5203 and decrement it by one. Store it in address 5203. Check the value $\left(\alpha_{H}-1\right)$, if it is non-zero then go to step-2 or else continue to next step. 
Step 12: Now load E register with ' $\delta_{\mathrm{H}}$ '.

Where $\delta_{\mathrm{H}}=\left\{\left(10_{\mathrm{H}} \times \omega_{\mathrm{H}}\right)-\left(10_{\mathrm{H}^{-}}-\omega_{\mathrm{H}}\right)\right\}$ and $\omega_{\mathrm{H}}$ is the number of rows of product matrix in hexadecimal.

Step 13: Load the HL pair with the 16-bit address which is obtained by adding $10_{\mathrm{H}}$ with the address of the last element of the product matrix.

Step 14: Clear A and B register and load c register with $10_{\mathrm{H}}$.

Step 15: Decrement the HL pair and add memory with A register.

Step 16: If there is a carry, store the carry in the $\mathrm{B}$ register. And decrement $\mathrm{C}$ register.

Step 17: If the value in $\mathrm{C}$ is non-zero go to step-15. Else continue to next step.

Step 18: Store the sum in memory. Increment the HL pair and store the carry in memory and then decrement HL pair.

Step 19: Decrement the $\mathrm{E}$ register. If the value in $\mathrm{E}$ is non-zero go to step-14. Else continue to next step.

Step 20: Repeat from step-14 to step-18 once.

Step 21: End the program.

$\underline{\text { Subroutine program }}$

Step 1: Load the content of the DE register pair.

Step 2: check if the value is zero. If it is zero, then jump to step-11. Else continue to the next step.

Step 3: Move the value to the $L$ register.

Step 4: Load the content of the BC register pair.

Step 5: Move the value to $\mathrm{H}$ register.

Step 6: Multiply the content of $\mathrm{H}$ and $\mathrm{L}$ register by multiple additions.

Step 7: Store the result in temporary storage.

Step 8: load the storage counter value from address 5200 to A and decrement it. Increment the B register by the value in A register.

Step 9: Recover the result from temporary storage and store the result in the area denoted by BC.

Step 10: Decrement the BC to previous value by using storage counter. 
Step 11: Increment the BC and DE by one.

Step 12: Load the value of columns in A from address 5201 and decrement it by one.

Step 13: Check for non-zero. If it is non-zero then go to step-1 or else continue to next step.

Step 14: Store the actual number of columns in address 5201.

Step 15: Return to the main program.

\section{$\underline{\text { FLOW CHART }}$}

Main program:

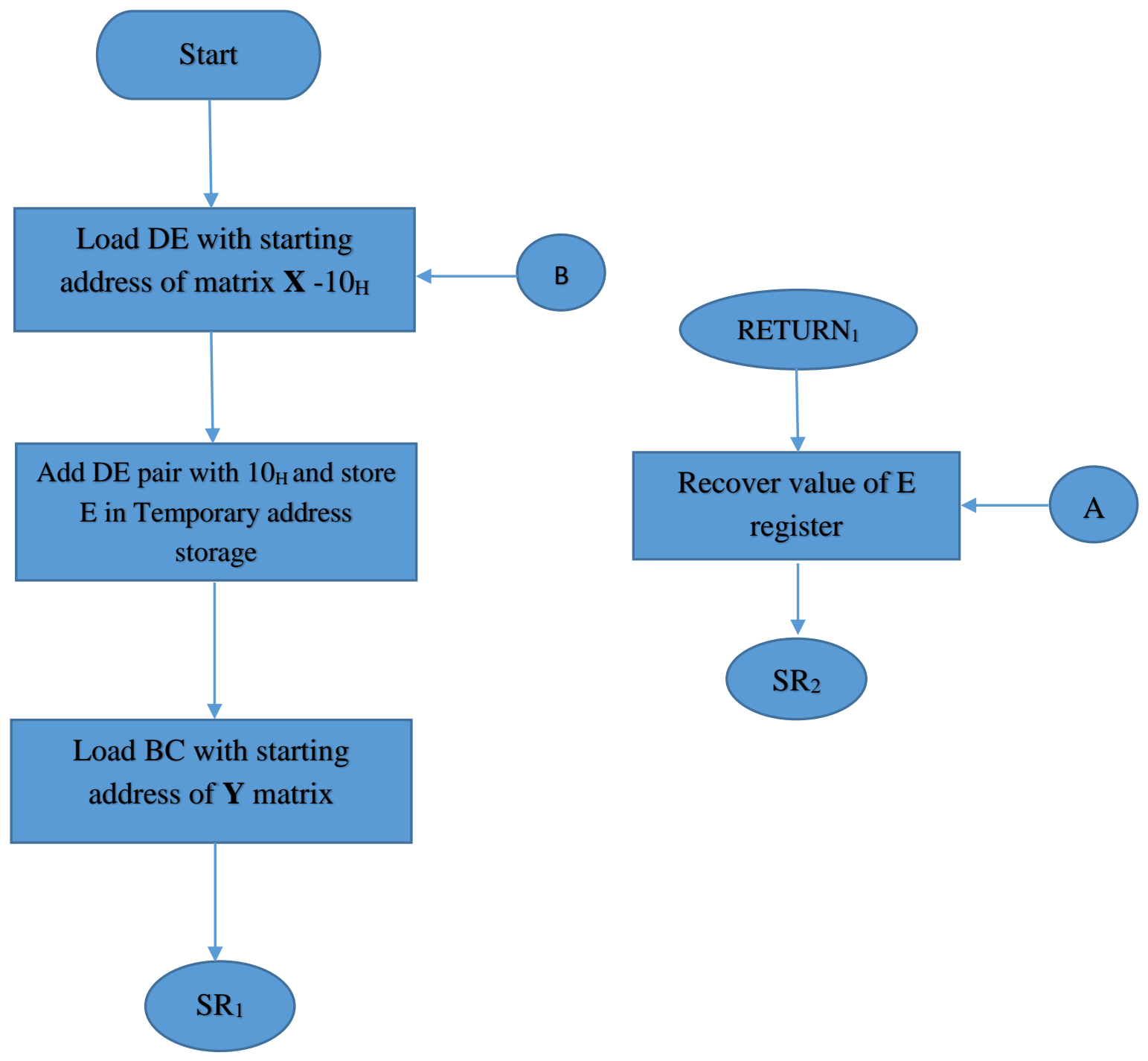




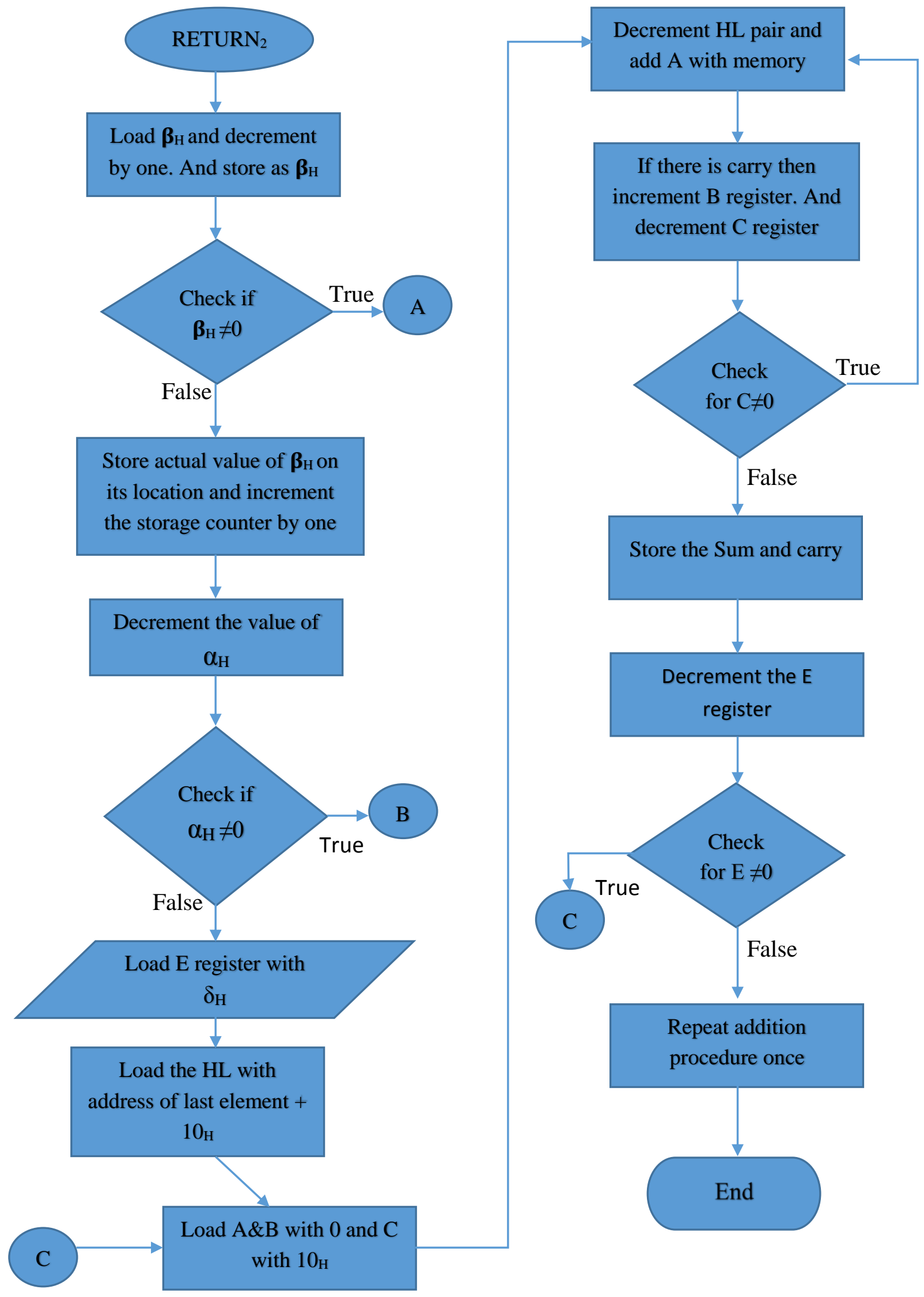


Subroutine program:

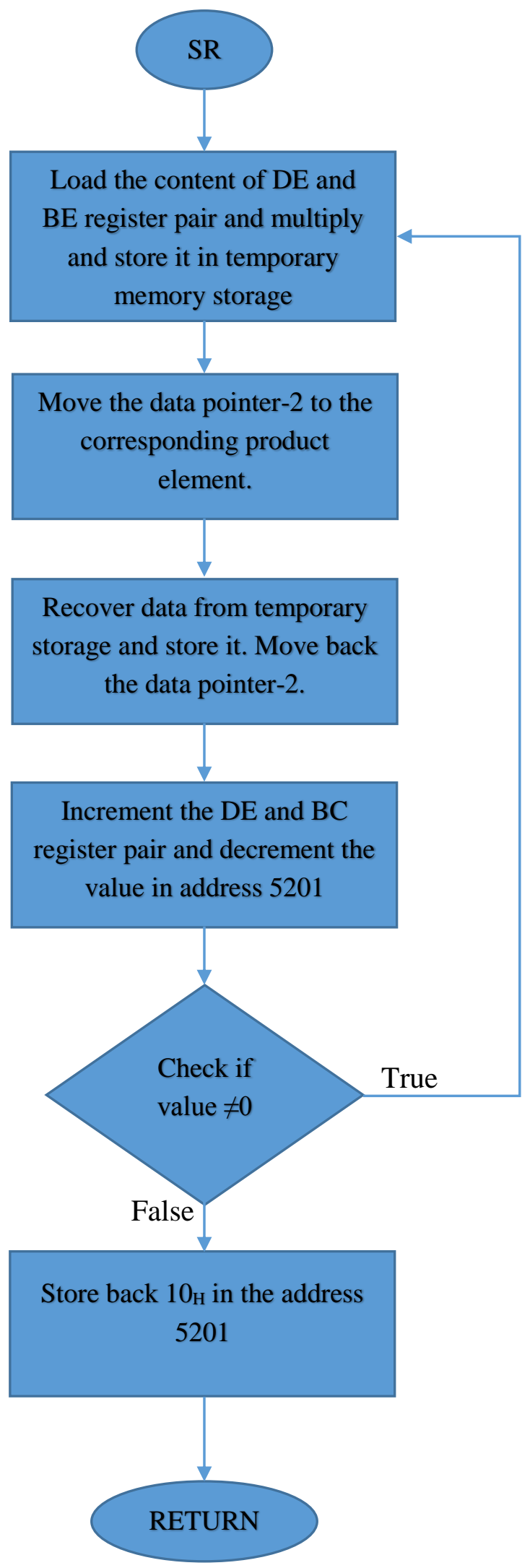




\section{CODING FOR MULTIPLICATION.}

$\underline{\text { Main program }}$

LXI D,40F0H

J2: LXI H,0010

DAD D

$\mathrm{XCHG}$

MOV A,E

STA $5301_{\mathrm{H}}$

LXI B, $4200_{\mathrm{H}}$

CALL S1

J1: LDA $5301_{\mathrm{H}}$

MOV E,A

CALL S1

LDA $5202_{\mathrm{H}}$

DCR A

STA $5202_{\mathrm{H}}$

JNZ J1

MVI A, $02 \mathrm{H}$

STA $5202_{\mathrm{H}}$

LDA $5200_{H}$

INR A

STA $5200_{\mathrm{H}}$

LDA $5301_{\mathrm{H}}$

MOV E,A

LDA $5203_{\mathrm{H}}$
DCR A

STA $5203_{\mathrm{H}}$

JNZ J2

MVI E,23

LXI H,4530H

J5: XRA A

MOV B,A

MVI C, $10_{\mathrm{H}}$

J4: DCX H

ADD M

JNC J3

INR B

J3: DCR C

JNZ J4

MOV M,A

INX H

MOV M,B

DCX H

DCR E

JNZ J5

XRA A

MOV B,A

MVI C, $10_{\mathrm{H}}$

J7: DCX H 
ADD M

JNC J6

INR B

J6: DCR C

JNZ J7

MOV M,A

INX H

MOV M,B

DCX H

HLT

$\underline{\text { Subroutine program }}$

S1: LDAX D

INR A

DCR A

JZ L1

MOV L,A

LDAX B

MOV H,A

XRA A

L2: ADD H

DCR L

JNZ L2
STA $5300_{H}$

LDA $5200_{\mathrm{H}}$

L4: DCR A

JZ L3

INR B

JMP L4

L3: LDA $5300_{\mathrm{H}}$

STAX B

LDA $5200_{\mathrm{H}}$

L5: DCR A

JZ L1

DCR B

JMP L5

L1: INX B

INX D

LDA $5201_{\mathrm{H}}$

DCR A

STA $5201_{\mathrm{H}}$

JNZ S1

MVI A, $10_{\mathrm{H}}$

STA $5201_{\mathrm{H}}$

RET

\section{INPUT}

For simplicity we can consider multiplier matrix $\mathbf{X}$ of order $(3 \times 16)$ and multiplicand matrix $\mathbf{Y}$ of order $(16 \times 3)$ with all the element as $01_{\mathrm{H}}$, In order to get a product matrix $\mathbf{X Y}$ of order $(3 \times 3)$. 
The program code given above written for this dimension by using conditions mentioned in Table. 4 and main algorithm step $12 \& 13$. Therefore the values of the parameters are:

$\alpha_{H}=03_{H}$

$\boldsymbol{\beta}_{\mathrm{H}}=02_{\mathrm{H}}$

$\omega_{\mathrm{H}}=03_{\mathrm{H}}$

$\delta_{\mathrm{H}}=23_{\mathrm{H}}$

But still, the program is capable of performing multiplication of maximum limit of $(16 \times 16)$ by changing the limits in Table 4 and the main algorithm step $12 \& 13$.

The reason we have chosen this kind of input matrix $\mathbf{X}$ and $\mathbf{Y}$ is to get the output as sooner as possible. If we compute the multiplication operation for maximum dimensional limit, the simulator will take a larger amount of time.

The simulation input of Matrix $\mathbf{X}$ is given in Fig. 10 .

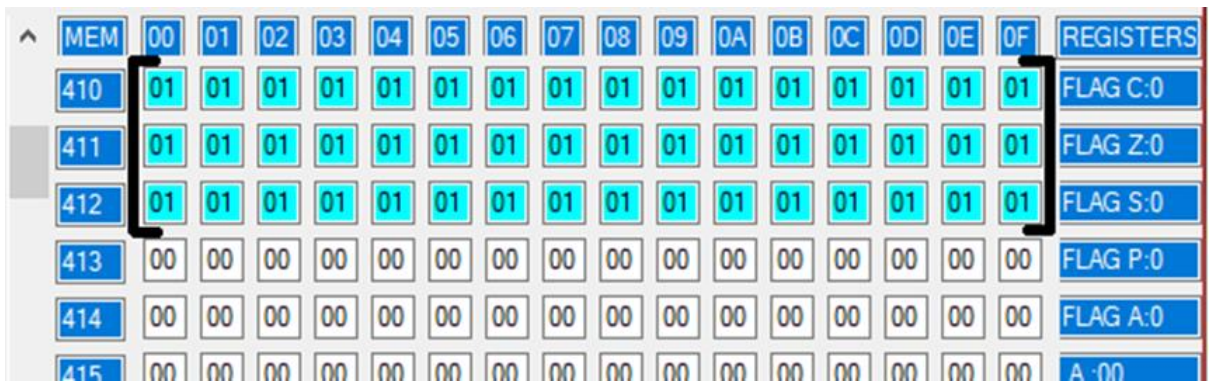

Fig. 9: Matrix X

The simulation input of Matrix $\mathbf{Y}^{\mathbf{T}}$ is given in Fig. 11.

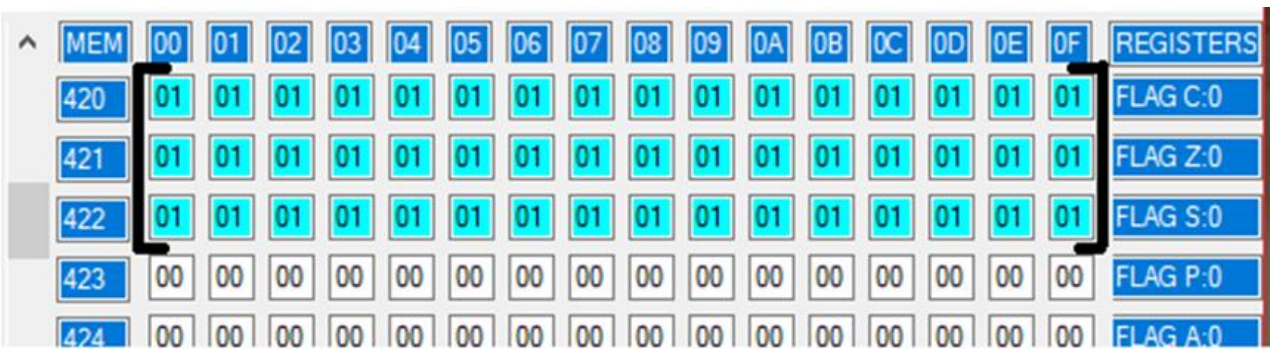

Fig. 10: Matrix $\mathrm{Y}^{\mathrm{T}}$

\section{OUTPUT}

The simulation output we obtained is shown in Fig.12, Fig.13, and Fig.14. Each Figure represents the corresponding row of the product matrix. 


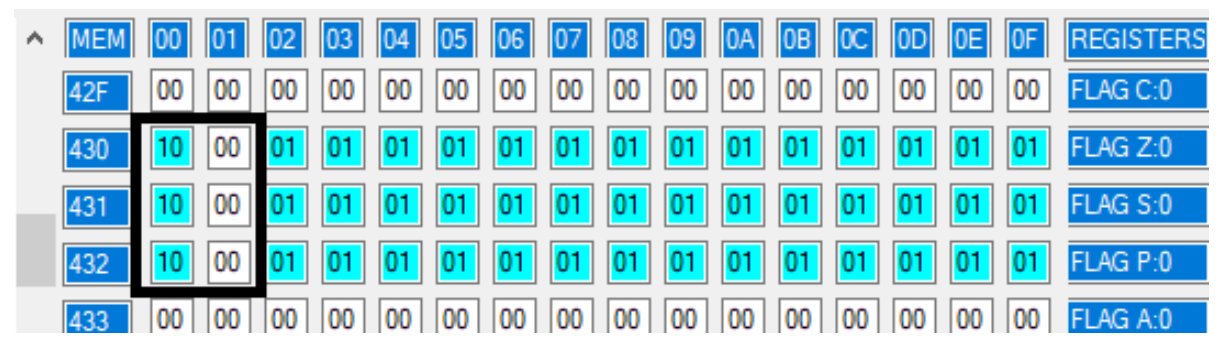

Fig. 11

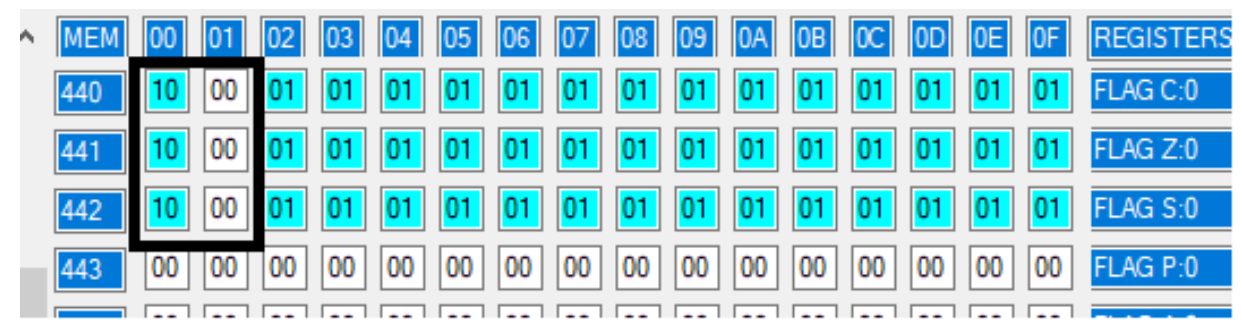

Fig. 12

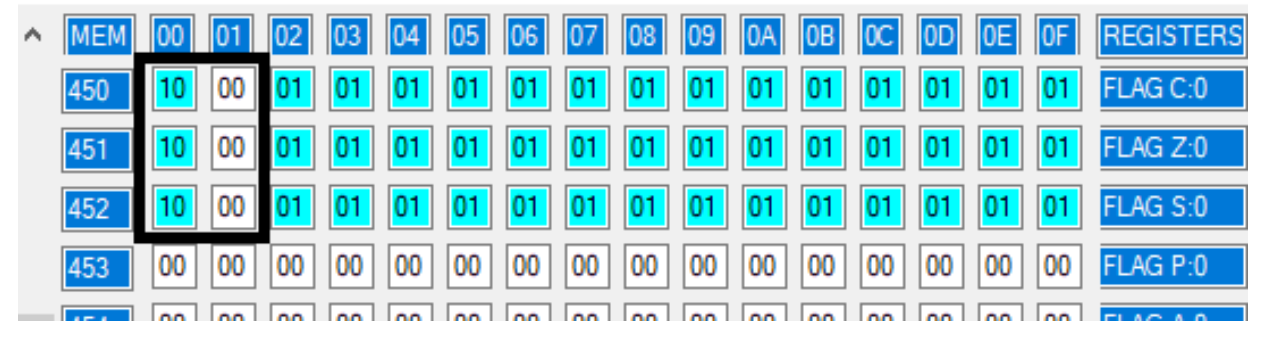

Fig. 13

Now we can use the Table. 3 to figure out the elements from the resultant values of the memories. The black-coloured box is marked to indicate the required memory area for the product matrix. It was not present in the simulator. The second (white) column inside the box indicates the overlapping value. It will be the first two digits of the corresponding element of the product matrix. By using the Table. 3 we can figure out the product matrix as

$$
X Y=\left[\begin{array}{lll}
0010_{H} & 0010_{H} & 0010_{H} \\
0010_{H} & 0010_{H} & 0010_{H} \\
0010_{H} & 0010_{H} & 0010_{H}
\end{array}\right]
$$

Therefore we successfully got the correct result.

\section{ADVANTAGE OF THIS HARDWARE COMPUTING}

- It is easy to add on the memory size, therefore we can do computations on n-dimensional matrices. 
- The size of the number we computing here is 8-bit, but it is physically easy to increase the size of the data bus.

- We can include decimal points and negative sign by designing a special flip-flop in each register and with few changes in ALU.

- Parallel computing can be done easily with fewer interfaces.

\section{CONCLUSION}

The Assembly language program for computing addition, subtraction and multiplication on higher dimensional matrix has been successfully designed. The possible operational limit of this algorithm is from $(2 \times 2)$ to $(16 \times 16)$ matrices. The time taken to complete execution is very long in actual 8085 microprocessor since we have small clock frequency oscillator. If we apply the same algorithm to the latest hardware systems we may get the result quickly.

\section{REFERENCES:}

1. V Vijayendran. "Fundamentals of Microprocessor-8085 Architecture Programming \& Interfacing", S. Viswanathan Printers \& Publishers Pvt. Ltd., Chennai, India (2009)

2. 8080/8085 Assembly Language Programming Manual Copyright (C) 1977, 1978 Intel Corporation, California, USA 